\title{
Disciplinary Consequence Differences in Grade 6 Students as a Function of Race, Ethnicity, and Economic Status
}

\author{
Myriam Quintero Khan \\ Spring Independent School District, TX \\ John R. Slate \\ Sam Houston State University
}

\begin{abstract}
In this investigation, we used Texas statewide data to determine the extent to which inequities were present in the assignment of school disciplinary consequences. Specifically examined were the assignment of in-school suspension, out-of-school suspension, and disciplinary alternative education program placement to grade 6 Black, Hispanic, and White students by their economic status in Texas public schools. Inferential analyses yielded statistically significant differences for each disciplinary consequence within each ethnic/racial group. Students who were economically disadvantaged received statistically significantly more instances of each disciplinary consequence than their same ethnic/racial peers who were not economically disadvantaged. Of note was the very high numbers of grade 6 students who were assigned these disciplinary consequences. A clear lack of equity was demonstrated in the assignment of disciplinary consequences to grade 6 Black, Hispanic, and White students by their economic status. As such, school administrators and educational leaders are urged to evaluate their own discipline programs to ascertain the degree to which they have equity in the assignment of disciplinary consequences in the students they serve.
\end{abstract}

Key words: Black, Hispanic, White, in-school suspension, out-of-school suspension, disciplinary alternative education program placement, inequities

Since the 1970s, numerous researchers have documented vast disparities in discipline by race and ethnicity in U.S. public schools (e.g., Allman \& Slate, 2011; Barnes \& Slate, 2016; Children's Defense Fund, 1975; Henkel, Slate, \& Martinez-Garcia, 2015; Jones, Slate, \& Martinez-Garcia, 2014, 2015; Hilberth \& Slate, 2014). Losen and Gillespie (2012) noted that the sus- pension rate of students doubled from 3.7\% in 1973 to $7.4 \%$ in 2010 (Porowski, O'Conner, \& Passa, 2014). Most notable is the high suspension rates of Black students, students of low economic status, and students with disabilities (Evans, Lester \& Anfara, 2010; Jones et al., 2014, 2015; Sullivan, Klingbeil, \& Van Norman, 2013). Black and Hispanic students who are in middle school are three times more likely than White students to be suspended or expelled from school (Dupper, 2010; Raffaele Mendez, Knoff, \& Ferron, 2002). Furthermore, at all three school levels (i.e., elementary, middle, and high school), one out of every six Black students was suspended at least once as compared with one in thirteen Native American students, one in fourteen Hispanic students, one in twenty White students, and one in fifty Asian American students (Losen \& Gillespie, 2012).

In 2014, the U.S. Department of Education's Office for Civil Rights released civil rights data that were collected from all 97,000 public schools in the United States and its 16,500 school districts for the 2011-2012 school year. Of the 49 million students in U.S. public schools, Black students were suspended at statistically significantly higher rates than were White students. Of particular concern is that the assignment of disciplinary consequences of Black students begins as early as preschool and persists throughout the different school levels. Specifically documented in this report is that Black students constituted $18 \%$ of preschool enrollment; however, $42 \%$ of Black students were suspended at least once and $48 \%$ of these Black students were suspended more than once (U.S. Department of Education, 2014, 2015). Furthermore, Black and Hispanic students and students of low economic status were significantly more likely to be suspended and expelled from school, drop out of school, and have less access to highly qualified teaching staff and rigor- 
ous curriculum than White students (U.S. Department of Education, 2014, 2015). This alarming trend is indicative of racial and ethnic disparities in discipline consequences that continue to be pervasive at the elementary, middle, and high school levels and create educational inequities among students of diverse racial and ethnic backgrounds (Henkel et al., 2015; Hilberth \& Slate, 2014; Jones et al., 2014, 2015; Shore, 2012).

With reference to Texas, the State of interest in this investigation, Hilberth and Slate (2014) documented that for the 2008-2009 school year, Black students enrolled at the middle school level (i.e., grades 6, 7, and 8 ) were two times more likely to be suspended and expelled than their White peers. Results from their study revealed an overrepresentation of Black middle school students assigned to in-school suspension, outof-school suspension, and disciplinary alternative education program placements than White middle school students. This overrepresentation of Black students and the potential academic ramifications are well documented in the literature (Fenning \& Rose, 2007; Gregory, Skiba, \& Noguera, 2010; Hilberth \& Slate, 2014; Jones et al., 2014, 2015; Skiba et al., 2011).

\section{Statement of the Problem}

Over the past 40 years, Black and Hispanic students have been overrepresented in the assignment of school disciplinary consequences when compared to White and Asian students (Fenning \& Rose, 2007; Gregory, Skiba, \& Noguera, 2010; Hilberth \& Slate, 2014; Jones et al., 2014, 2015; Shore, 2012; Skiba et al., 2011). Additionally, a disproportionate number of economically disadvantaged urban middle school students have been more likely to receive stricter disciplinary consequences than suburban middle school students (Evans et al., 2010; Noguera, 2003; Skiba, Michael, Nardo, \& Peterson, 2002). Overrepresentation of Black, Hispanic, and impoverished students in exclusionary disciplinary consequences have contributed to inequities in education and expanded the achievement gap for students of diverse racial and ethnic backgrounds (Hilberth \& Slate, 2012, 2014; Jones et al., 2014, 2015).

\section{Purpose of the Study}

The purpose of this study was to examine the extent to which differences in the proportion of Black, Hispanic, and White grade 6 students were assigned to a discipline consequence in Texas public schools. Specifically examined was the impact of student economic status on school assignment of in-school suspension, out-of-school suspension, and disciplinary alternative education program placements for Black, Hispanic, and White students.

\section{Research Questions}

The following research questions were addressed in this investigation: (1) What is the difference in the percentage of Black students, Hispanic students, and White students in grade 6 who were assigned to inschool suspension as a function of their economic status; (2) What is the difference in the percentage of Black students, Hispanic students, and White students in grade 6 who were assigned to out-of-school suspension as a function of their economic status; and (3) What is the difference in the percentage of Black students, Hispanic students, White students in grade 6 who were assigned to a disciplinary alternative education program placement as a function of their economic status? These research questions refer to whether similar or dissimilar percentages of students are assigned to a discipline consequence, regardless of their economic status. When dissimilar percentages within each ethnic group are assigned a discipline consequence by student economic status, then inequities would be present.

\section{Definition of Terms}

For purposes of this study, four terms are essential to define: (1) In-school suspension was defined by the U.S. Department of Education (2014) as "instances in which a child is temporarily removed from his/her regular classroom(s) for disciplinary purposes but remains under the direct supervisor of school personnel" (p. 80). (2) Out-of-school suspension was defined by the Texas Education Agency (2010) as the removal of students from the regular classroom as a disciplinary consequence; a consequence that follows the use of in-school suspension. In an out-of-school suspension, students are removed from school for at least one day but not to exceed three consecutive days. (3) The third method of disciplinary consequence-one that follows an in-school suspension and an out-of-school suspension-is a disciplinary alternative education program placement. In a disciplinary alternative education program placement, students are removed from their regular classes because of disciplinary reasons and placed in a separate class. This class setting may be located either on or off of the regular school campus (Texas Education Agency, 2010). (4) The State of Texas uses the federal government's guidelines to determine whether students are economically disadvantaged or not. The income eligibility guidelines are:

The family-size income levels prescribed annually by the Secretary of Agriculture for determining eligi- 
bility for free and reduced price meals and free milk. The free guidelines are at or below $130 \%$ of the federal poverty guidelines. The reduced price guidelines are between 130 and at or below $185 \%$ of the federal poverty guidelines (Child and Nutrition Programs, 2015, p. 10).

\section{Method}

\section{Participants}

Participants in this study included a total of 341,411 grade 6 students from Texas traditional public middle schools in the 2011-2012 school year. Of this total, 46,560 were Black, 179,638 were Hispanic, and 115,213 were White. Data regarding student racial and ethnic membership were obtained from the Texas Education Agency Public Education Information Management System, which is a reporting system that collects data from individual school districts regarding student and personnel demographics, academic performance, and financial and organizational information and reports it to the Texas Education Agency (2006). Through a public information request form, the Texas Education Agency provided the following information: student ethnicity and race; student economic status; and whether or not students had received an in-school suspension, an out-of-school suspension, or a disciplinary alternative education program placement.

\section{Data Analysis}

In this investigation, both the independent variables and the dependent variables were categorical in nature. Three independent variables were present: inschool suspension, out-of-school suspension, and disciplinary alternative education program placement. Each of these three independent variables was comprised of two groups: students that received a specific consequence or students that did not receive that specific consequence. The dependent variable used for each of these three independent variables was economic status of students: they either qualified for the free or reduced lunch program or did not qualify for the program. The sample of students differed for each of these analyses, with the analyses being conducted separately for Black, Hispanic, and White students.

The optimal inferential statistical procedure when both the independent variable and the dependent variable are categorical (i.e., in this study, they were all specifically dichotomous variables) is the Pearson chisquare (Field, 2013). The degree to which the percentages of students differentially received an in-school suspension, an out-of-school suspension, or a disciplinary alternative education program placement by their economic status was ascertained in each of the Pearson chi-square procedures that were calculated. Given the large sample size and the independence of data, the underlying assumptions of this procedure were met (Field, 2013).

\section{Results}

Each of the previously delineated research questions will now be addressed, with in-school suspension for Black, Hispanic, and White students by their economic status being discussed first. Following the in-school suspension results will be the out-of-school suspension findings for Black, Hispanic, and White students by their economic status. Finally, the results for disciplinary alternative education program placements for Black, Hispanic, and White students by their economic status will be presented.

For the first research question for Black students, the result was a statistically significant difference, $x^{2}$ $(1)=819.26, p<.001$. The effect size for this finding was small, $\varphi=.13$ (Cohen, 1988). Revealed in Table 1 is that $33.5 \%$ of Black students who were economically disadvantaged received an in-school suspension compared to $19.93 \%$ of Black students who were not economically disadvantaged. Readers should note the numbers of grade 6 Black students who received an in -school suspension: 11,400 Black students who were economically disadvantaged and 2,499 Black students who were not economically disadvantaged. Readers are referred to Table 1 for the frequencies and percentages of in-school suspension by student economic status.

Regarding the first research question for Hispanic students, the result was a statistically significant difference, $X 2(1)=1309.84, p<.001$. The effect size for this finding was trivial, $\varphi=.085$ (Cohen, 1988). Revealed in Table 1 is that $20.2 \%$ of Hispanic students who were economically disadvantaged received an inschool suspension compared to $12.0 \%$ of Hispanic students who were not economically disadvantaged. Readers should note the high numbers of grade 6 Hispanic students who received an in-school suspension: 28,818 Hispanic students who were economically disadvantaged and 4,415 Hispanic students who were not economically disadvantaged.

Similarly for White students, the result was also statistically significant, $\chi 2(1)=4225.28, p<.001$. The effect size for this finding was small, $\varphi=.19$ (Cohen, 1988). As noted in Table 1, 23.1\% of White students who were economically disadvantaged received an inschool suspension compared to $8.9 \%$ of White students who were not economically disadvantaged. 
Table 1

Frequencies and Percentages of In-School Suspension for Grade 6 Black, Hispanic, and White Students by Economic Status

\begin{tabular}{ccc}
\hline & $\begin{array}{c}\text { Received In-School Suspension } \\
\text { Ethnicity/Race and Economic Status } \\
\text { Black Students }\end{array}$ & $\begin{array}{c}\text { Did Not Receive an In-School } \\
\text { Suspension }\end{array}$ \\
Economically Disadvantaged & $(n=11,400) 33.5 \%$ & $\underline{n \text { and \% age of Total }}$ \\
Not Economically Disadvantaged & $(n=2,499) 19.93 \%$ & $(n=22,585) 66.5 \%$ \\
Hispanic Students & $(n=28,818) 20.2 \%$ & $(n=10,076) 80.1 \%$ \\
Economically Disadvantaged & $(n=4,415) 12.0 \%$ & $(n=113,952) 79.8 \%$ \\
Not Economically Disadvantaged & & $(n=32,453) 88.0 \%$ \\
White Students & $(n=7,623) 23.1 \%$ & $(n=25,423) 76.9 \%$ \\
Economically Disadvantaged & $(n=7,279) 8.9 \%$ & $(n=74,888) 91.1 \%$ \\
Not Economically Disadvantaged & & \\
\hline
\end{tabular}

Though lower numbers than for Black and Hispanic students, high numbers of Grade 6 White students were assigned to an in-school suspension: 7,623 White students who were economically disadvantaged and 7,279 White students who were not economically disadvantaged.

With respect to the second research question for Black students, the result was a statistically significant difference, $\chi 2(1)=828.67, p<.001$. The effect size for this finding was small, $\varphi=.13$ (Cohen, 1988). Revealed in Table 2 is that $21.3 \%$ of Black students who were economically disadvantaged received an out-ofschool suspension compared to $9.7 \%$ of Black students who were not economically disadvantaged. Readers should note the strong disparity in these percentages and in the numbers of grade 6 Black students who received an out-of-school suspension: 7,237 Black students who were economically disadvantaged and 1,221 Black students who were not economically disadvantaged. Readers are referred to Table 2 for the frequencies and percentages of out-of-school suspension by student economic status.

Concerning the second question for Hispanic students, the result was a statistically significant difference, $\chi^{2}(1)=946.08, p<.001$. The effect size for this finding was trivial, $\varphi=.073$ (Cohen, 1988). Presented in Table 2 is that $9.0 \%$ of Hispanic students who were economically disadvantaged received an out-of-school suspension compared to $4.1 \%$ of Hispanic students who were not economically disadvantaged. Readers should note the high numbers of grade 6 Hispanic students who received an out-of-school suspension: 12,855 Hispanic students who were economically disadvantaged and 1,522 Hispanic students who were not economically disadvantaged.

Similarly for White students, the result was also statistically significant, $\chi 2(1)=1526.92, p<.001$. The effect size for this finding was small, $\varphi=.12$ (Cohen, 1988). As indicated in Table 2, $6.4 \%$ of White students who were economically disadvantaged received an out-of-school suspension compared to $1.9 \%$ of White students who were not economically disadvantaged. Comparatively lower numbers of White students received an out-of-school suspension than did Black and Hispanic students. The number of grade 6 White students who were assigned to an in-school suspension was 2,101 who were economically disadvantaged and 1,557 who were not economically disadvantaged.

With respect to the third research question for 
Table 2

Frequencies and Percentages of Out-of-School Suspension for Grade 6 Black, Hispanic, and White Students by Economic Status

\begin{tabular}{|c|c|c|}
\hline & $\begin{array}{c}\frac{\text { Received an Out-of-School Sus- }}{\text { pension }} \\
\underline{n \text { and } \% \text { age of Total }}\end{array}$ & $\begin{array}{c}\frac{\text { Did Not Receive an Out-of- }}{\underline{\text { School Suspension }}} \\
\underline{n \text { and \%age of Total }}\end{array}$ \\
\hline \multicolumn{3}{|l|}{$\begin{array}{l}\text { Ethnicity/Race and Economic Status } \\
\text { Black Students }\end{array}$} \\
\hline Economically Disadvantaged & $(n=7,237) 21.3 \%$ & $(n=26,748) 78.7 \%$ \\
\hline Not Economically Disadvantaged & $(n=1,221) 9.7 \%$ & $(n=11,354) 90.3 \%$ \\
\hline \multicolumn{3}{|l|}{ Hispanic Students } \\
\hline Economically Disadvantaged & $(n=12,855) 9.0 \%$ & $(n=129,915) 91.0 \%$ \\
\hline Not Economically Disadvantaged & $(n=1,522) 4.1 \%$ & $(n=35,346) 95.9 \%$ \\
\hline \multicolumn{3}{|l|}{ White Students } \\
\hline Economically Disadvantaged & $(n=2,101) 6.4 \%$ & $(n=30,945) 93.6 \%$ \\
\hline Not Economically Disadvantaged & $(n=1,557) 1.9 \%$ & $(n=80,610) 98.1 \%$ \\
\hline
\end{tabular}

Black students, the result was a statistically significant difference, $X 2(1)=162.79, p<.001$. The effect size for this finding was trivial, $\varphi=.06$ (Cohen, 1988). Revealed in Table 3 is that $4.0 \%$ of Black students who were economically disadvantaged received a disciplinary alternative education program placement compared to $1.6 \%$ of Black students who were not economically disadvantaged. Readers should note the number of Grade 6 Black students who were economically disadvantaged and received this consequence: 1,373 students. Readers are referred to Table 3 for the frequencies and percentages of disciplinary alternative education program placement by student economic status.

Concerning the third research question for Hispanic students, the result was a statistically significant difference, $\chi 2(1)=299.52, p<.001$. The effect size for this finding was trivial, $\varphi=.04$ (Cohen, 1988). Present in Table 3 is that $2.2 \%$ of Hispanic students who were economically disadvantaged received a disciplinary alternative education program placement compared to $0.8 \%$ of Hispanic students who were not economically disadvantaged. Readers should note the very high number of grade 6 Hispanic students who were economically disadvantaged and received this conse- quence: 3,192 students.

Similarly for White students, the result was also statistically significant, $x 2(1)=758.46, p<.001$. The effect size for this finding was trivial, $\varphi=.08$ (Cohen, 1988). As indicated in Table 3, 2.1\% of White students who were economically disadvantaged received a disciplinary alternative education program placement compared to $0.4 \%$ of White students who were not economically disadvantaged. Comparatively lower numbers of White students were assigned to this disciplinary consequence than were Black and Hispanic students. The number of grade 6 White students who were assigned to a disciplinary alternative education program placement was 691 who were economically disadvantaged and 334 who were not economically disadvantaged.

\section{Discussion}

In this empirical investigation, we used Texas statewide data to determine the extent to which inequities were present in the assignment of disciplinary consequences. Specifically examined were the assignment of in-school suspension, out-of-school suspension, and disciplinary alternative education program placement to grade 6 Black, Hispanic, and White stu- 
Table 3

Frequencies and Percentages of Disciplinary Alternative Education Program Placement for Grade 6 Black, Hispanic, and White Students by Economic Status

$\begin{array}{lc}\underline{\text { Received a DAEP }} & \text { Did Not Receive a DAEP } \\ \underline{n \text { and } \% \text { age of Total }} & \underline{n \text { and } \% \text { age of Total }}\end{array}$

Ethnicity/Race and Economic Status

Black Students

Economically Disadvantaged

Not Economically Disadvantaged

Hispanic Students

Economically Disadvantaged

Not Economically Disadvantaged

White Students

Economically Disadvantaged

Not Economically Disadvantaged $(n=3,192) 2.2 \%$

$(n=309) 0.8 \%$ $(n=13,9578) 97.8 \%$

$(n=36,559) 99.2 \%$

$$
\begin{array}{ll}
(n=1,373) 4.0 \% & (n=32,612) 96.0 \% \\
(n=205) 1.6 \% & (n=12,370) 98.4 \%
\end{array}
$$

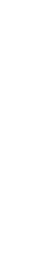


alternative education program placements were assigned almost six times more often to students in poverty than to students who were not economically disadvantaged.

Results of our statewide investigation are congruent with the suspension rates of Black students and of students of low economic status (Evans et al., 2010; Hilberth \& Slate, 2012, 2014; Jones et al., 2014, 2015; Sullivan et al., 2013). Our findings were, unfortunately, even more robust than the findings of Dupper (2010) and Raffaele Mendez et al. (2002), who documented that Black and Hispanic students in middle school were three times more likely than were White students to be suspended or expelled from school. Results from this study are commensurate with Hilberth and Slate (2014) who established that Black students enrolled at the middle school level were two times more likely to be suspended and expelled than their White peers. This overrepresentation of Black students and potential academic ramifications are well documented in the literature (Fenning \& Rose, 2007; Gregory et al., 2010; Hilberth \& Slate, 2014; Jones et al., 2014, 2015; Skiba et al., 2011).

\section{Conclusion}

A clear lack of equity was demonstrated in the assignment of disciplinary consequences to Grade 6 Black, Hispanic, and White students by their economic status. For in-school suspension, out-of-school suspension, and disciplinary alternative education program placement, strong inequities were present not only in the assignment of these consequences by student race and ethnicity, but also by student economic status. Students in poverty were assigned disciplinary consequences many times more often than students who were not in poverty. Educational leaders, policymakers, and researchers are encouraged to examine the issue of discipline with respect to equity and disparate impact.

We are not aware of any empirical literature in which students in poverty were determined to misbehave more often than children who were not in poverty. As such, the underlying reasons for the inequities we documented need to be investigated. We believe that a lack of cultural or social capital may be present, meaning that students in poverty may lack the experience or knowledge they need to behave in accordance with school norms (Silva, 2001). Silva (2001), among other authors, contended that parent educational levels and socioeconomic status are primary influences on their children's success at school. If this lack of cultural capital is present, then educational leaders need to consider developing education- al strategies and discipline methods that recognize this lack of cultural capital as well as generate ways to improve it. We also believe that a disconnect may exist between the culture of most teachers (i.e., White) and the culture of minority students (i.e., primarily Hispanic and Black students in Texas). Bone and Slate (2011) summarized the primary arguments in support of a more diverse teacher workforce, particularly given the increases in student diversity. We believe that our data provide even more support for a need for a more diverse teacher workforce.

Given the inequities in the assignment of the three major disciplinary techniques used in U.S. schools as a function of student economic status, we contend that changes need to be made in discipline methods. Instead of methods that exclude students from the classroom environment, educators must generate discipline techniques that do not interfere with student opportunity to learn. Until such time, it appears that children will continue to be removed from the classroom settings, not only on the basis of their behavior, but also based upon their ethnicity, race, and economic status.

\section{References}

Allman, K., \& Slate, J. R. (2011). School discipline in public education: A brief review of current practices. International Journal of Educational Leadership Preparation, 6(2). Retrieved from http:/ / www.ncpeapublications.org/volume-6number-2/386-school-discipline-in-public-education-abrief-review-of-current-practices.html

Barnes, M. J., \& Slate, J. R. (2016). Grade 4 and 5 inequities in disciplinary consequences by ethnicity/race and gender. Journal of Global Research in Education and Social Science, 5(4), 216-221.

Bone, J. A., \& Slate, J. R. (2011). Student ethnicity, teacher ethnicity, and student achievement: On the need for a more diverse teacher workforce. Journal of Multiculturalism in Education. Retrieved from http://www.wtamu.edu/webres/File/ Journals/MCJ/Volume\% 207-1/Bone $\% 20$ and $\% 20$ Slate $\%$ 20-\%20Need\%20for\%20Minority\%20Teachers.pdf

Child and Nutrition Programs. (2015, July). Eligibility manual for school meals: Determining and verifying eligibility. Retrieved from www.fns.usda.gov\%2Fschool-meals \%2Fincomeeligibility-guidelines\&usg

Children's Defense Fund. (1975). School suspensions: Are they helping children? Cambridge, MA: Washing-ton Research Project. Retrieved from http://eric.ed.gov/?id=ED115648Fabelo

Cohen, J. (1988). Statistical power analysis for the behavioral sciences (2nd ed.). Hillsdale, NJ: Lawrence Erlbaum.

Dupper, D. R. (2010). Does the punishment fit the crime? The impact of zero tolerance discipline on at-risk youths. Children $\mathcal{E}$ Schools, 32(2), 67-69.

Evans, K., Lester, J., \& Anfara, Jr., V. A. (2010). Classroom management and discipline: Responding to the needs of young adolescents. Middle School Journal, 41(3), 56-63. 
Field, A. (2013). Discovering statistics using IBM SPSS statistics (4th ed.) Thousand Oaks, CA: Sage.

Fenning, P., \& Rose, J. (2007). Overrepresentation of African Americans students in exclusionary discipline: The role of school policy. Urban Education, 42(6), 536-559. doi: $10.1177 / 0042085907305039$

Gregory, A., Skiba, R. J., \& Noguera, P. A. (2010). The achievement gap and the discipline gap: Two sides of the same coin? Educational Researcher, 39(1), 59-68. doi:10.3102/0013189X09357621

Henkel, B. L., Slate, J. R., \& Martinez-Garcia, C. (2015). Disciplinary Alternative Education Program placement and academic achievement by student gender and ethnicity/race. International Research Journal for Quality in Education, 2(12), 1125. Available online at http://

www.worldresearchjournals.com/higheredupprrcv.aspx

Hilberth, M., \& Slate, J. R. (2012). Disciplinary consequences and their effects on academic achievement for Texas Grade 6 African American and White students. Journal of Theory and Practice in Education, 8(1), 120-141. Retrieved from http://eku.comu.edu.tr/eku_eski/index/8/1/ mhilberth_jrslate.pdf

Hilberth, M., \& Slate, J. R. (2014). Middle school Black and White Student assignment to disciplinary consequence: A clear lack of equity. Education and Urban Society, 46(3), 312-328. doi: $10.1177 / 0013124512446218$

Jones, M. C., Slate, J. R., \& Martinez-Garcia, C. (2014). Discipline inequities between White and Hispanic middle school students: An analysis of the research literature. Journal of Ethical Educational Leadership, 1(6). Retrieved from http:/ / cojeel.org/wp-content/uploads/2013/06/

JEELvo1no6.pdf

Jones, M. C., Slate, J. R., \& Martinez-Garcia, C. (2015). School discipline and Grade 6 Hispanic and White student academic performance: A statewide investigation. Progress in Education, Volume 32. Hauppauge, NY: Nova Publishers.

Losen, D. J., \& Gillespie, J. (2012). Opportunities suspended: The disparate impact of disciplinary exclusion from school. Retrieved from http://civilrightsproject.ucla.edu/resources/ projects/center-for-civil-rights-remedies/school-to-prison -folder/federal-reports/ upcoming-ccrr-research

Noguera, P. A. (2003). Schools, prison, and social implications of punishment: Rethinking disciplinary practices. Theory in Practice, 42(4), 341-350.

Porowski, A., O'Conner, R., \& Passa, A. (2014). Disproportionality in school discipline: An assessment of trends in Maryland, 200912 (REL 2014-017). Washington, DC: U.S. Department of Education, Institute of Education Sciences, National Center for Education Evaluation and Regional Assistance, Regional Educational Laboratory Mid-Atlantic. Retrieved from http://www.ies.ed.gov/ncee/edlabs/regions/ midatlantic/pdf/REL_2014017.pdf

Raffaele Mendez, L. M., Knoff, H. M., \& Ferron, J. M. (2002). School demographic variables and out-of-school suspension rates: A quantitative and qualitative analysis of a large, ethnically diverse school district. Psychology in the Schools, 39(3), 259-277. doi: 10.1002/ pits.10020

Silva, A. (2001). Cultural capital and educational attainment. Sociology, 35(4), 893-912.
Skiba, R., Michael, R. S., Nardo, A. C., \& Peterson, L. R. (2002). The color of discipline: sources of racial and gender disproportionality in school punishment. The Urban Review, 34 (4). 317-342. Retrieved from http://www.indiana.edu/ requity/docs/ColorofDiscipline2002.pdf

Skiba, R. J., Horner, R. H., Chung, C. G., Rausch, M. K., May, S. L., \& Tobin, T. (2011). Race is not neutral: A national investigation of African American and Latino disproportionality in school discipline. School Psychology Review, 40(1), 85107. Retrieved from http://youthjusticenc.org/ download/education-justice/disparities/Race $\% 20$ is $\%$ 20not\%20Neutral.pdf

Sullivan, A. L, Klingbeil, D. A., \& Van Norman, E. R. (2013). Beyond behavior: Multilevel analysis of the influence of sociodemographics and school characteristics on students' risk of suspension. School Psychology Review, 42(1), 99-114.

Texas Education Agency. (2006). Public Education Information Management System Overview. Retrieved from http:/ / tea.texas.gov/index4.aspx?id=3541

Texas Education Agency. (2010). Education Code 37. Alternative settings for behavior management. Retrieved from http:// www.statutes.legis.state.tx.us/Docs/ED/htm/ ED.37.htm

U.S. Department of Education. (2014). Expansive survey of America's public schools reveals troubling racial disparities: Lack of access to pre-school, greater suspensions cited [Press release]. Retrieved from http://www.ed.gov/news/press-releases/ expansive-survey-americas-public-schools-revealstroubling-racial-disparities

U.S. Department of Education. (2015). School climate and discipline. Retrieved from http://www2.ed.gov/policy/gen/guid/ school-discipline/index.html 